\title{
Glutaraldehyde-Induced Chemical Colitis Versus Ischemic Colitis
}

\author{
Joseph C. Yarze
}

Published online: 13 February 2010

(C) Springer Science+Business Media, LLC 2010

\section{To the Editor,}

Dr. Ahishali and colleagues have recently (Dec 2009 issue) reported on three cases of presumed glutaraldehydeinduced chemical colitis [1]. In describing glutaraldehydeinduced colitis, the authors appropriately suggest that the colonoscopic findings are nonspecific and may mimic those seen in ischemic colitis, inflammatory bowel disease, and infectious colitis. In describing case \#2 (which I agree was in fact related to glutaraldehyde-induced chemical colitis), the authors suggest that transabdominal Doppler interrogation of the mesenteric artery was performed, and as no pathologic findings were noted, a diagnosis of ischemic colitis was excluded. This suggestion is both misleading and incorrect.

Although Doppler interrogation of the mesenteric artery can be useful in attempting to evaluate for acute mesenteric ischemia (from, for example, thrombosis of the superior mesenteric artery), a normal result does not necessarily exclude ischemic colitis. Ischemic colitis is considered to most frequently be a spontaneous event, without major mesenteric vessel occlusion, and this disorder is believed to be "low-flow" and nonocclusive in nature [2]. As such, in the usual case of ischemic colitis, the results of mesenteric Doppler interrogation (or even angiography) will be normal. The authors' thoughts in this regard would be welcome.

\section{References}

1. Ahishali E, Uygur-Bayramicili O, Dolapcioglu C, et al. Chemical colitis due to glutaraldehyde: case series and review of the literature. Dig Dis Sci. 2009;54:2541-2545.

2. Boley SJ. Colon ischemia-25 years later. Am J Gastroenterol. 1990;8:931-935.
J. C. Yarze $(\square)$

Gastroenterology Associates of Northern New York, Glens Falls, NY, USA

e-mail: bopus@roadrunner.com 